\title{
Staging for Prostate Cancer
}

\section{Time to Incorporate Pretreatment Prostate-specific Antigen and Gleason Score?}

\author{
Mack Roach III, MD ${ }^{1,2}$ \\ Vivian Weinberg, $\mathrm{PhD}^{1,3}$ \\ Howard Sandler, ${ }^{4}$ \\ lan Thompson, $\mathrm{MD}^{5}$
}

\begin{abstract}
${ }^{1}$ Department of Radiation Oncology, University of California San Francisco Comprehensive Cancer Center, University of California San Francisco, San Francisco, California.

${ }^{2}$ Department of Urology, University of California San Francisco Comprehensive Cancer Center, University of California San Francisco, San Francisco, California.

${ }^{3}$ Biostatistics Core, University of California San Francisco Comprehensive Cancer Center, University of California San Francisco, San Francisco, California.

${ }^{4}$ Department of Radiation Oncology, University of Michigan, Ann Arbor, Michigan.

${ }^{5}$ Department of Urology and San Antonio Cancer Institute, University of Texas San Antonio, San Antonio, Texas.
\end{abstract}

\begin{abstract}
Address for reprints: Mack Roach III, MD, Department of Radiation Oncology, University of California San Francisco Comprehensive Cancer Center, 1600 Divisadero Street, Suite 1031, San Francisco, CA 94143-1708; Fax: (415) 353-9883; E-mail: roach@radonc17.ucsf.edu
\end{abstract}

Received August 31, 2006; revision received October 10, 2006; accepted October 16, 2006.
BACKGROUND. The American Joint Committee on Cancer (AJCC) staging system for prostate cancer is based primarily based on clinical tumor ( $\mathrm{T}$ ) classification. In this article, the authors summarize arguments for incorporating additional pretreatment parameters and creating a new staging system for prostate cancer.

METHODS. Men with localized prostate cancer who received treatment with external beam radiation alone were analyzed using the 1997 AJCC staging system compared with a system that included pretreatment prostate-specific antigen (pPSA) level and Gleason score (GS). Multivariate analyses using a Cox proportional-hazards model were carried out to evaluate T classification, GS, and pPSA as predictors of overall survival (OS), disease-specific survival (DSS), and freedom from PSA failure (FFPF).

RESULTS. Based on pretreatment characteristics in a series of contemporary patients, only $0.6 \%$ of patients were classified with AJCC stage I disease, $16.0 \%$ were classified with AJCC stage III disease, and $83.4 \%$ were classified with AJCC stage II disease. Multivariate analyses indicated the independent statistical significance of T classification, GS, and pPSA in predicting OS, DSS, and FFPF (model chi-square value, $P<.0001$ for each). Using these 3 predictors, subsets of patients who had similar outcomes were combined to provide examples of the insensitivity of the AJCC system for predicting outcomes. Incorporating pPSA and GS allowed the identification of differences in OS, DSS, and FFPF for subsets of patients with AJCC stage II disease $(P<.0001, P=.005$, and $P<.0001$, respectively).

CONCLUSIONS. The current AJCC staging system does not divide contemporary patients with prostate cancer into prognostic subgroups and does not identify patients who have comparable biochemical control and survival. The AJCC staging system for prostate cancer should be changed to incorporate pPSA, GS, and risk stratification. Cancer 2007;109:213-20. (C) 2006 American Cancer Society.

KEYWORDS: prostate cancer, American Joint Committee on Cancer staging system, long-term survival, prostate-specific antigen.

deally physicians should be able to apply the American Joint

Committee on Cancer (AJCC) staging system for prostate cancer to estimate the risk of cancer recurrence and survival. Historically, tumor $(\mathrm{T})$ classification, lymph node $(\mathrm{N})$ status, and the presence of metastases (M) have been the cornerstones of staging for solid tumors. Unfortunately, the exclusive use of the current TNM staging system has limited relevance to predicting outcome and directing therapy for men with clinically localized prostate cancer. In part, this limitation is because nearly $75 \%$ of men who currently are diagnosed with clinically localized prostate cancer have nonpalpable disease, and the incidence of lymph node involvement is $<4 \%$ in men who undergo radical prostatectomy. ${ }^{1}$ 
Most clinicians agree on how to identify which patients have the lowest and highest risk of developing a disease recurrence. It is the intermediate AJCC subset that is most heterogeneous in terms of outcomes, including biochemical failure and survival. Clearly, the current staging system is inadequate and could be improved by incorporating reproducible prognostic factors. In this article, we propose a change in the AJCC staging system that improves its relevance to newly diagnosed patients with prostate cancer. In doing so, we hope to improve the ability of physicians and patients to communicate, compare outcomes, and select the most appropriate treatment. By accomplishing this feat, we hope to foster greater uniformity when multi-institutional comparisons are made.

Recent studies have shown that the serum level of prostate-specific antigen (PSA) is associated with the presence of occult prostate cancer, even in men with normal levels. ${ }^{2}$ More than 10 years ago, it also became clear that the pretreatment PSA (pPSA) level was the most important predictor of biochemical (PSA) recurrence after radiotherapy. For $>10$, years it has been known that the Gleason score (GS) was the most important predictor of death., ${ }^{3,4}$ Recognition of the value of combing these 2 factors with T classification to create prognostic risk groups followed shortly thereafter. ${ }^{4-7}$ Over the last few years, PSA has been confirmed as an important predictor of mortality from prostate cancer. ${ }^{8-12}$

Ideally, a large, multicenter, prospective registration trial should be used to define and validate a new staging system. In the meantime, we believe that there are enough data currently available to justify practical changes to the AJCC system. Herein, we suggest some characteristics of a new staging system based on literature published in major peer-reviewed journals that incorporate the best evidence available and the current practice patterns.

\section{MATERIALS AND METHODS}

\section{Evidence Supporting the Incorporation of PSA and GS}

The comparative analysis presented here was based on data from 912 patients who received treatment for localized prostate cancer between 1987 and 1998 at the University of California San Francisco and at the University of Michigan. ${ }^{13}$ Patients with metastatic disease who received radiation therapy up to a maximum dose $<60$ grays (Gy), who received neoadjuvant or adjuvant hormone therapy, or who had no PSA follow-up after external beam radiotherapy (EBRT) and patients with missing pPSA, GS, or T classification information were excluded from this analysis. To
TABLE 1

Distribution of Patients (N = 912)

\begin{tabular}{llll}
\hline & \multicolumn{3}{c}{ No. of patients (\%) } \\
\cline { 2 - 4 } AJCC Stage & GS 2-6* & GS 7 & GS 8-10 \\
\hline Stage I & & & \\
$\quad$ T1 & $5(0.6)^{*}$ & - & - \\
Stage II & & & \\
T1-T2 & $493(54)$ & $205(22)$ & $63(7)$ \\
$\quad$ pPSA $<10 \mathrm{ng} / \mathrm{mL}$ & 248 & 79 & 14 \\
pPSA $10 \mathrm{ng} / \mathrm{mL}-<20 \mathrm{ng} / \mathrm{mL}$ & 136 & 66 & 23 \\
pPSA $\geq 20 \mathrm{ng} / \mathrm{mL}$ & 109 & 60 & 26 \\
Stage III & & & \\
T3 & $47(5)$ & $57(6)$ & $41(5)$ \\
$\quad$ pPSA $<20 \mathrm{ng} / \mathrm{mL}$ & 27 & 20 & 13 \\
pPSA $\geq 20 \mathrm{ng} / \mathrm{mL}$ & 20 & 37 & 29 \\
\hline
\end{tabular}

AJCC indicates American Joint Committee on Cancer staging system; GS, Gleason score; pPSA, pretreatment prostate-specific antigen level; T, clinical tumor classification.

* AJCC stage I includes only GS 2-4.

evaluate biochemical failure, patients who had $<2$ years of follow-up from the end of EBRT who did not have evidence of biochemical, local, or distant disease recurrence also were excluded. The early failures or deaths that were caused by prostate cancer were included, thus minimizing the risk of inflating early estimates of freedom from PSA failure (FFPF). This resulted in a cohort with complete information on pPSA, GS, and T classification and with adequate follow-up, with $95 \%$ of the patients treated prior to 1997, so that all patients could be classified by multiple risk definitions to compare differences in outcome. The distribution according to AJCC stage, T classification, GS, and pPSA is presented in Table 1.

The median follow-up from the end of EBRT for surviving patients was 69 months with $47 \%$ of patients surviving for $>6$ years and $24 \%$ surviving $>8$ years. Regular PSA follow-up measurements were obtained approximately every 3 to 6 months. Patients were treated with either conventional $(21 \%)$ or 3 dimensional (3D) conformal radiotherapy (79\%), as determined by their physician, to maximum doses that ranged from $60 \mathrm{~Gy}$ to $87.3 \mathrm{~Gy}$. The median maximum dose was 70 Gy for conventional radiotherapy and $70.4 \mathrm{~Gy}$ for 3D conformal radiotherapy.

The American Society of Therapeutic Radiation Oncology consensus definition of biochemical failure, which requires 3 consecutively increasing PSA measurements, was applied to determine $\mathrm{FFPF}^{14}$ According to this definition, the date of failure was modified to be the midpoint between the first of the 3 rising PSA levels and the date of the PSA obtained prior to the 3 rising values. Failures also included 
patients with local or distant disease $(\mathrm{n}=59)$, patients who died with prostate cancer $(\mathrm{n}=4)$, patients who received any hormone intervention prior to a PSA failure $(n=33)$, and patients who had a marked increase in PSA within the timing or routine follow-up $(\mathrm{n}=12)$. If no failure occurred, then patients were censored at the date of the last PSA follow-up. Death from any cause determined overall survival (OS). Death from prostate cancer (diseasespecific survival [DSS]) was determined from a review of death certificates and hospital charts. Patients who had metastatic disease at the time of death were classified as having died of prostate cancer, even if other causes were listed as contributing factors. Patients who did not die were censored as of the date of last contact. All failure endpoints (OS, DSS, and FFPF) were measured from the end of EBRT.

\section{Statistical Analysis}

The Kaplan-Meier product-limit method was used to estimate the probability of biochemical failure and survival. ${ }^{15}$ The log-rank test was used to formally compare the distributions of time to failure for subsets of the AJCC staging groups or according to the newly proposed staging system. In an attempt to develop a new staging system that expanded the AJCC staging system beyond the current method, which is based primarily on $\mathrm{T}$ classification, multivariate analyses were conducted. A Cox proportional-hazards model with a stepwise forward technique was used to evaluate T classification, GS, and pPSA simultaneously as predictors of OS, DSS, and FFPF. ${ }^{16}$ These 3 potential predictors were treated categorically so that we would be able to define subsets of these features for patients who had a comparable risk of failure. GS and pPSA were not considered as continuous variables, because this would be assuming a constant proportional-hazard ratio over the range of values. Indicator variables were used for each of these 3 factors by using traditional cut-off points (T1-T2 and T3; GS 2-6, GS 7, and GS 8-10; and pPSA $<10 \mathrm{ng} /$ $\mathrm{mL}$, from $10 \mathrm{ng} / \mathrm{mL}$ to $<20 \mathrm{ng} / \mathrm{mL}$, and $\geq 20 \mathrm{ng} / \mathrm{mL}$ ). The patients who were included in this analysis were classified initially according to the 1997 fifth edition of the AJCC classification system, in which stage I includes patients with Tla tumors and a GS from 2 to 4; stage II includes patients with Tla tumors and a GS from 5 to 10 and patients with T1b, T1c, or T2 tumors; and stage III includes patients with T3 tumors). ${ }^{17}$ The likelihood ratio (LLR) test was used to compare models to determine which factors were significant, independent predictors of outcome. Subsets were combined based on nonsignificant log-rank tests to identify subsets of patients that had a similar risk of death or biochemical failure.

\section{RESULTS}

Only $0.6 \%$ of patients were classified with AJCC stage I disease, and $16 \%$ were classified with AJCC stage III disease; thus, the majority of patients were classified with AJCC stage II disease (83.4\%). Because only 5 patients were classified with AJCC stage I disease, this subset is not included in the statistical comparisons described below. FFPF, DSS, and OS differed significantly between AJCC stage II and stage III ( $P$ $<.0001$ for all 3 endpoints). The 5 -year estimates of FFPF, DSS, and OS for patients with AJCC stage II disease were $54 \%, 96 \%$, and $87 \%$, respectively; for patients with AJCC stage III disease, the FFPF, DSS, and OS estimates were $18 \%, 83 \%$ and $71 \%$, respectively. Further discrimination within AJCC risk groups II and III also can be observed by considering the 3 GS subsets (2-6, 7, and 8-10) within each T-classification group. Again, significant differences in FFPF, DSS, and OS were observed for patients with AJCC stage II disease $(P<.0001, P=.0004$, and $P=.0001$, respectively). This indicates that the AJCC stage II group represents pooled subsets of patients with variable outcomes. For patients with T3 disease, the patients with AJCC stage III disease, a difference in FFPF according to GS occurred (GS $2-6$ vs 7 vs $8-10$; $P=.01$ ). Death occurred at the same rate among the T3 subsets, reflecting the fact that $82 \%$ of the patients were diagnosed with a GS $\geq 7$ and/or a pPSA $\geq 20 \mathrm{ng} / \mathrm{mL}$.

The AJCC staging groups were also subdivided according to pPSA $(<10$, from $10 \mathrm{ng} / \mathrm{mL}$ to $<20 \mathrm{ng} /$ $\mathrm{mL}$, and $\geq 20 \mathrm{ng} / \mathrm{mL}$ ). Again, the inclusion of pPSA demonstrated that the current staging system is inadequate, as indicated by the significant differences in FFPF, DSS, and OS for the patients with AJCC stage disease caused by their pPSA level $(P<.0001, P=.0003$, and $P=.0003$, respectively). A difference in biochemical failure also can be observed between pPSA $<20 \mathrm{ng} / \mathrm{mL}$ and PSA $\geq 20$ $\mathrm{ng} / \mathrm{mL}$ in patients with AJCC stage III disease $(P$ $=.002)$.

Multivariate analysis indicated the strong independent statistical significance of $\mathrm{T}$ classification, GS, and pPSA in predicting FFPF (model LLR test: $P<0001)$. Analyses were repeated with the outcome variables changed to reflect later endpoints in disease progression; again, the results indicated the independent, statistically significant benefit of a $\mathrm{Tl}$ or $\mathrm{T} 2$ tumor classification and a pPSA level $<20 \mathrm{ng} / \mathrm{mL}$ in predicting DSS and OS (model LLR test: $P<.0001$ 
TABLE 2

Proposed "New" Prostate Cancer Staging System

\begin{tabular}{ll}
\hline Classification & Definition \\
\hline TX & Tumor cannot be assessed \\
T0 & No evidence of primary tumor \\
Tis & Carcinoma in situ \\
New stage I & T1-T2, GS $\leq 6$, and PSA $<10 \mathrm{ng} / \mathrm{mL}$ \\
New stage II & T1-T2, GS $\leq 6$, and PSA $<10-20 \mathrm{ng} / \mathrm{mL}$ \\
& Or T1-T2, GS 7, and PSA $<20 \mathrm{ng} / \mathrm{mL}$ \\
Stage IIA & T1-T2, GS $\leq 6$, and PSA $10-<20 \mathrm{ng} / \mathrm{mL}$ \\
Stage IIB & T1-T2, GS 7, and PSA $<20 \mathrm{ng} / \mathrm{mL}$ \\
New stage III & T1-T2, GS $\leq 6$, and PSA $\geq 20 \mathrm{ng} / \mathrm{mL}$ \\
& Or T1-T2, GS 7, and PSA $\geq 20 \mathrm{ng} / \mathrm{mL}$ \\
& Or T1-T2 and GS 8-10 \\
Stage IIIA & Or clinical T3 disease \\
& T1-T2, GS $\leq 6$, and PSA $\geq 20 \mathrm{ng} / \mathrm{mL}$ \\
Stage IIIB & Or T1-T2, GS 8-10, and PSA $<20 \mathrm{ng} / \mathrm{mL}$ \\
Stage IIIC & T1-T, GS $\geq 7$, and PSA $\geq 20 \mathrm{ng} / \mathrm{mL}$ \\
NX & Clinical T3 disease, seminal vesicle or bladder neck invasion \\
N0 & Lymph nodes cannot be assessed \\
N1 & No regional lymph node involved \\
\hline
\end{tabular}

GS indicates Gleason score; PSA, prostate-specific antigen.

for both endpoints). Among the patients with AJCC stage II disease, controlling for the T-classification effect, both GS and pPSA were significant independent predictors of all 3 outcomes (model LLR tests: FFPF, $P<.0001$; DSS, $P=.0005$; OS, $P<.0001$ ). Among the patients with AJCC stage III disease, which is the T3 group, pPSA levels $\geq 20 \mathrm{ng} / \mathrm{mL}$ and a GS from 8 to 10 were significant independent predictors of poorer FFPF (model LLR test: $P=.0006$ ). Receiving a diagnosis of T3 disease, regardless of GS or PPSA, indicated poor DSS or OS.

Combinations of subsets according to $\mathrm{T}$ classification, GS, and pPSA for patients with AJCC stage II and stage III disease were defined by using the results for predictors of DSS that were identified in the Cox multivariate model described above. There was no difference in DSS among patients who had $\mathrm{T} 1$ or T2 tumors and a GS from 2 to 6 between those with a pPSA level of $<10 \mathrm{ng} / \mathrm{mL}$ and a pPSA from 10 $\mathrm{ng} / \mathrm{mL}$ to $<20 \mathrm{ng} / \mathrm{mL}(P=.60)$. The final combination of subsets was based on nonsignificant log-rank tests, resulting in 3 distinct new risk groups (Table 2 ), hereafter referred to as the new stages. This new staging system is predictive of OS, DSS, and FFPF (log-rank test; $P<0001$ for all 3 endpoints) and does not indicate a strictly additive model of predictors.

By applying this new system, 28\% (rather than $0.6 \%$ ) of contemporary patients would have a more favorable outcome with 5-year estimates of FFPF, DSS, and OS for patients with newly diagnosed stage
I prostate cancer of $72 \%, 98 \%$, and $89 \%$, respectively (data not shown). In addition, $26 \%$ of patients would be identified as having an increased risk of failure compared with the AJCC stages. Only $47 \%$ of patients would be classified similarly by both staging systems, and this would include all patients with T3 tumors (16\%). The shifts in classification are limited to all but 1 patient with AJCC stage II disease. As is shown, the new staging definition, as shown in Figure 1A, $1 \mathrm{~B}$, and 1C), identifies a greater proportion of the patients with AJCC II disease who would be at a reduced risk of failure and death than would be anticipated by the current AJCC criteria. Distinct prognostic subsets can be identified within AJCC stage groups II and III based on GS and pPSA. Among patients who had AJCC stage II disease with an overall 5-year DSS probability of $96 \%$, there was a significant difference when the new staging system was used for the analysis $(P=.005)$. The 5 -year estimates of DSS for the 3 new stages ( 1 through 3 ) were $98 \%, 98 \%$, and $93 \%$ (Fig. 1C). This new staging system also indicated a significant difference in FFPF with 5-year estimates for the new stages of $72 \%$, $52 \%$, and $37 \%$ (Fig. 1A), respectively, and a significant difference in OS, with 5-year estimates of $89 \%, 92 \%$, and $81 \%$ (Fig. 1B) for patients with AJCC stage II disease $(P<.0001$ for each). All of these T3 patients are at increased risk of failure, but a subset of them with a GS from 8 to 10 and pPSA $\geq 20 \mathrm{ng} / \mathrm{mL}$ was identified that had a poorer outcome, especially in terms of FFPF $(P=.003)$ and DSS $(P=.01)$. Among patients with AJCC III who had an $18 \%$ FFPF at 5 years, this higher risk subset of the new stage III patients had a significantly poorer outcome, with an only $10 \%$ FFPF rate at 5 years compared with $20 \%$ for patients who did not have both of these unfavorable features at diagnosis (data not shown). Similarly, with an overall $83 \%$ 5-year DSS rate, the estimate was $71 \%$ for the higher risk subset compared with $86 \%$ for the remaining AJCC stage III (T3) patients. Thus, this new staging system has identified subsets of patients within both the stage II and stage III AJCC groups that had similar outcomes and who are at greatest risk of failure.

\section{DISCUSSION}

Despite the widespread recognition of serum PSA as a marker for the presence of disease, for the extent of disease, and as a prognostic factor for recurrence and death, to date, the PSA level has not been incorporated into the current staging system. Similarly, GS not only has been known as a predictor of pathologic stage but may be the most important predictor of 
death from prostate cancer. It, too, largely has been ignored in the current AJCC staging system.

Because of widespread PSA screening, the predominance of nonpalpable (T1c) disease, and declines in the use of transurethral resection of the prostate, this staging system may no longer be adequate for classifying contemporary patients. In parti-
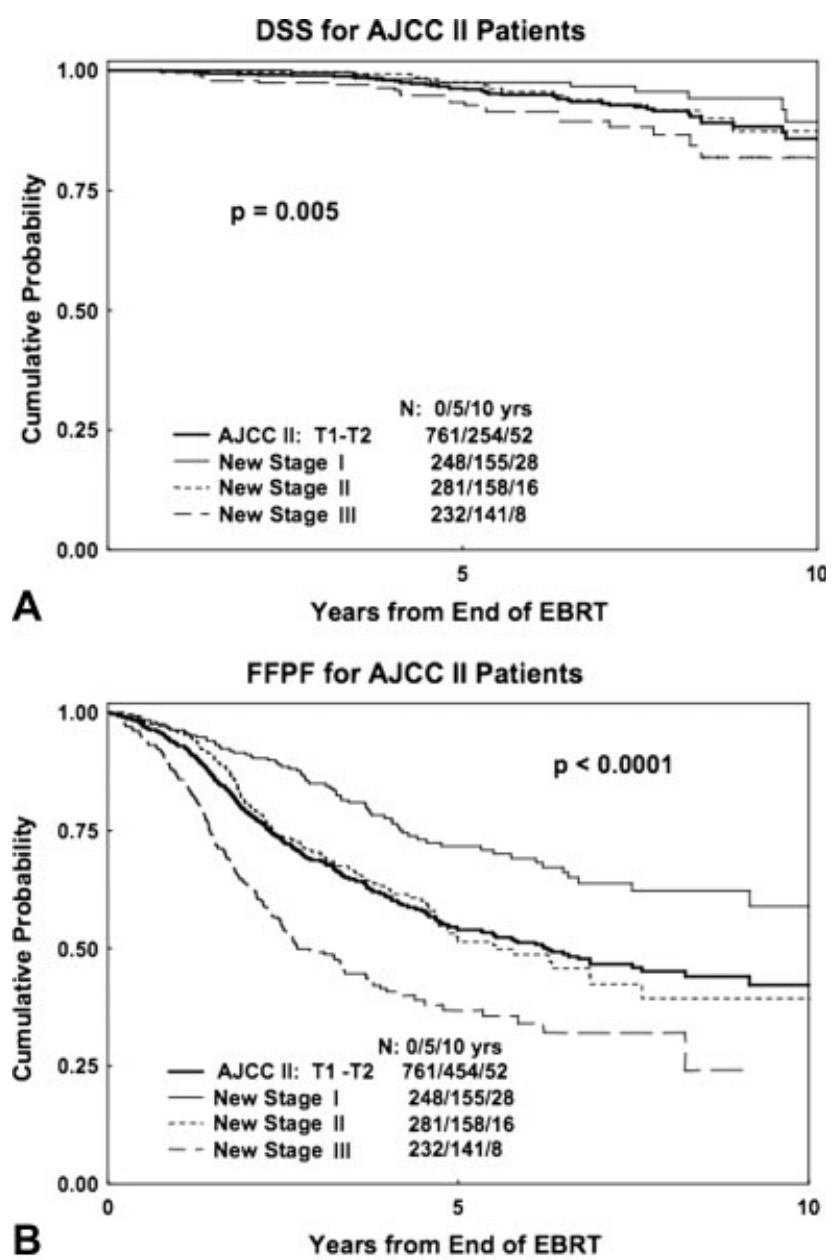

B

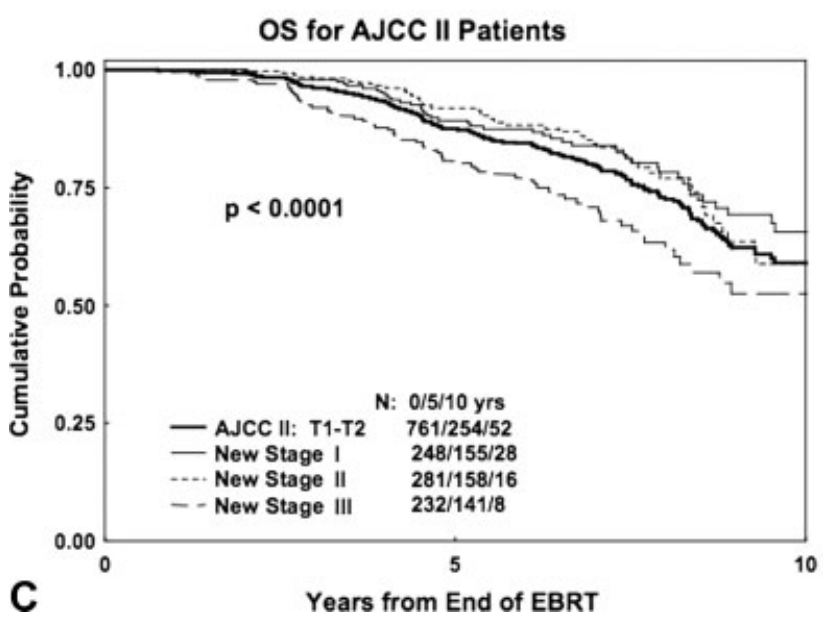

cular, patients with AJCC stage I prostate cancer (clinical stage Tla with a GS from 2 to 4) rarely are diagnosed, so that newly diagnosed patients essentially are being classified as either having or not having clinical stage T3 disease (palpable extension beyond the prostate). Thus, as the frequency of diagnosing clinical T3 tumors decreases, the majority of currently diagnosed patients are classified as with AJCC stage II prostate carcinoma, and these patients do not have a uniform prognosis. For this group of patients, other disease features, including GS, pPSA levels, and the percentage of positive biopsies, are strong, independent predictors of pathologic stage and outcome. This has led to the practice of combining these and other features to identify subsets of patients with similar outcomes.

There is general agreement about how to identify patients at the lowest and highest risk of disease recurrence. It is the intermediate AJCC subset that is most heterogeneous in terms of outcomes, including biochemical failure and survival. Clearly, the current staging system is inadequate and could be improved by incorporating these reproducible prognostic factors. The objective of this article was to propose a change in the AJCC staging system that would improve its relevance to patients who are newly diagnosed with prostate cancer. In doing so, we hope to improve the ability of physicians and patients to communicate, compare outcomes, and select the most appropriate treatment.

\section{A Practical Solution Based on the Standard of Care?}

Currently, there is a compelling body of evidence to support the notion that pPSA and GS should now move beyond risk-stratification systems and also should be incorporated into our staging system. In response to the shortcomings of the current AJCC staging system for prostate cancer, the medical community, in a sense, has voted with their feet. Risk stratification has become the mantra for predicting

FIGURE 1. Among patients with American Joint Committee on Cancer stage II (AJCC II) prostate cancer, who have an overall 5-year disease-specific survival (DSS) probability of $96 \%$, there was a significant difference according the analysis with the new staging system $(P=.005)$. The new system also indicated significant differences in freedom from prostate-specific antigen failure (FFPF), with 5-year estimates for new stages I through III of $72 \%, 52 \%$, and $37 \%$, respectively (A), and significant differences in overall survival (OS), with 5 -year estimates of $89 \%, 92 \%$, and $81 \%$ (B), respectively $(P<.0001$ for each). The 5 -year estimates of DSS for new stages I through III were $98 \%, 98 \%$, and $93 \%$, respectively (C). EBRT indicates external beam radiotherapy. 
TABLE 3

Criteria for Defining Low-risk Patients from Selected Modern Radiotherapy Series

\begin{tabular}{|c|c|c|c|c|c|}
\hline Institution(s) (Alphabetical Order) & Reference(s) & T Classification & GS & PSA & Comments \\
\hline Canadian multicenter study & Crook et al., $2004^{18}$ & $\mathrm{~T} 1-\mathrm{T} 2 \mathrm{a}$ & $\leq 6$ & $<10 \mathrm{ng} / \mathrm{mL}$ & $\begin{array}{l}\text { Prospective Phase III trial evaluating } \\
\text { 3-mo vs 8-mo NHT }\end{array}$ \\
\hline CAPSURE & Cooperberg et al., $2003^{19}$ & T1-T2a & $\leq 6$ & $\leq 10 \mathrm{ng} / \mathrm{mL}$ & $\begin{array}{l}\text { Longitudinal data from } 30 \text { academic and } \\
\text { community-based urology practices }\end{array}$ \\
\hline \multicolumn{6}{|l|}{ Cleveland Clinic and Mercy } \\
\hline Medical Center & Kupelian et al., $2004^{20}$ & T1-T2a & $\leq 6$ & $<10 \mathrm{ng} / \mathrm{mL}$ & Used to compare EBRT with PPI \pm EBRT to RP \\
\hline FCCC & Lattanzi et al., $1997^{21}$ & $\mathrm{~T} 1-\mathrm{T} 2$ & $2-7$ & $<8 \mathrm{ng} / \mathrm{mL}$ & Predictors of outcome after 3DCRT \\
\hline FCCC & Chism et al., $2004^{22}$ & $\mathrm{~T} 1-\mathrm{T} 2 \mathrm{c}$ & $\leq 6$ & $<10 \mathrm{ng} / \mathrm{mL}$ & Compared single vs multiple factors \\
\hline Harvard Joint Center & D'Amico et al., $1998^{5}$ & Tlc-T2a & $\leq 6$ & $\leq 10 \mathrm{ng} / \mathrm{mL}$ & Used to compare EBRT to PPI and RP \\
\hline Harvard Joint Center & D'Amico et al., 2002, 2004 ${ }^{23,24}$ & Tlc-T2a & $\leq 6$ & $\leq 10 \mathrm{ng} / \mathrm{mL}$ & PPBs $>50 \%$ vs $<50 \%$ correlated with outcome \\
\hline Harvard, MGH & Zietman et al., $2004^{25}$ & $\mathrm{~T} 1-\mathrm{T} 2$ & $\leq 6$ & $<10 \mathrm{ng} / \mathrm{mL}$ & 10-y results comparing favorable with unfavorable \\
\hline MD Anderson & Selek et al., $2003^{26}$ & T1-T2a & $\leq 6$ & $<10 \mathrm{ng} / \mathrm{mL}$ & $\begin{array}{l}\text { PPBs }>50 \% \text { vs }<50 \% \text { did not correlated } \\
\text { independently with outcome }\end{array}$ \\
\hline Mount Sinai & Lee et al., $2002^{27}$ & T1-T2a & $\leq 6$ & $<10 \mathrm{ng} / \mathrm{mL}$ & Patients treated with PPI \pm EBRT and NHT \\
\hline MSKCC & Potters et al., $2004^{28}$ & $\mathrm{~T} 1-\mathrm{T} 2$ & $\leq 6$ & $\leq 10 \mathrm{ng} / \mathrm{mL}$ & Also used PPB $<50 \%$ and cores to stratify \\
\hline MSKCC & Zelefsky et al., $1998,2002^{29,30}$ & $<\mathrm{T} 2 \mathrm{c}$ & $\leq 6$ & $\leq 10 \mathrm{ng} / \mathrm{mL}$ & Studies using 3DCRT and IMRT \\
\hline Seattle Prostate & Sylvester et al., $2003^{31}$ & $<\mathrm{T} 2 \mathrm{c}$ & $\leq 6$ & $\leq 10 \mathrm{ng} / \mathrm{mL}$ & $\begin{array}{l}\text { Compares outcomes using different } \\
\text { definitions after PPI }\end{array}$ \\
\hline $\begin{array}{l}\text { US Multiinstitutional prostate } \\
\text { cancer database }\end{array}$ & Kuban et al., $2003^{32}$ & T1b, T1c, T2a & $\leq 6$ & $\leq 10 \mathrm{ng} / \mathrm{mL}$ & $\begin{array}{l}\text { Long-term follow-up of }>4000 \text { patients } \\
\text { who received EBRT }\end{array}$ \\
\hline WBRC (Australia) & Williams et al., $2004^{33}$ & T1c-T2a & $\leq 6$ & $\leq 10 \mathrm{ng} / \mathrm{mL}$ & $\begin{array}{l}\text { Compares this grouping with those by Pisansky, } \\
\text { Shipley and Leibel }\end{array}$ \\
\hline Wheeling West Virginia & Merrick et al., $2002^{34}$ & T1c-T2a & $\leq 6$ & $\leq 10 \mathrm{ng} / \mathrm{mL}$ & $\begin{array}{l}\text { PPI } \pm \text { EBRT also analyzed by } \\
\text { PPBs }<34 \%, 34-50 \% \text {, and }>50 \%\end{array}$ \\
\hline
\end{tabular}

T indicates tumor; GS, Gleason score; PSA, prostate-specific antigen; NHT, neoadjuvant hormone therapy; CAPSURE, Cancer of the Prostate Strategic Urologic Research Endeavor; EBRT, external beam radiotherapy; PPI, permanent prostate seed implantation; \pm , with or without; RP, radical prostatectomy; FCCC, Fox Chase Cancer Center; 3DCRT, 3-dimensional conformal radiotherapy; PPBs, percent positive biopsies; MGH, Massachusetts. General Hospital; M D Anderson: The University of Texas M. D. Anderson Cancer Center; MSKCC, Memorial Sloan-Kettering Cancer Center; IMRT, intensity-modulated radiotherapy; WBRC, William Buckland Radiotherapy Center (Melbourne, Australia).

TABLE 4

Criteria for Defining Low-risk Patients from Selected Modern Radiotherapy Series

\begin{tabular}{|c|c|c|c|c|c|}
\hline Institution(s) (Alphabetical Order) & Reference(s) & T Classification & GS & PSA, ng/mL & Comments \\
\hline MSKCC & Kattan et al., $2000^{7}$ & T1c-T2a* & $\leq 6^{*}$ & $\leq 10^{*}$ & $\begin{array}{l}\text { Based on nomogram using these } \\
\text { parameter similar results* }\end{array}$ \\
\hline RTOG & Roach et al., $2000^{4}$ & T1-T2 & $\leq 6$ & $\mathrm{NA}$ & RTOG risk groups \\
\hline RTOG & Michalski et al., $1999^{35}$ & T1-T2 & $\leq 6^{\dagger}$ or 7 & $\leq 15^{\dagger}$ or $<5$ & Calculated risk of positive SV $<15 \% *$ \\
\hline UCSF and UM & Speight et al., $1999^{36}$ & NA & - & -5 & Calculated risk of positive lymph nodes $<15^{\ddagger}$ \\
\hline UCSF and UM & Roach et al., $2000^{37}$ & NA & $-\$$ & $-\$$ & Calculated risk of ECE $<34 \%$ vs $34-66 \%$ vs $>66 \%$ \\
\hline UCSF and UM & Roach et al., $2003^{8}$ & T1-T2 & $\leq 6$ & $<10$ vs $10-<20$, vs $\geq 20$ & RTOG risk groups \\
\hline
\end{tabular}

T indicates tumor; GS, Gleason score; PSA, prostate-specific antigen; MSKCC, Memorial Sloan-Kettering Cancer Center; RTOG, Radiation Therapy Oncology Group; NA, not available; RTOG, Radiation Therapy Oncology Group; SV, seminal vesicles; USCF, University of California San Francisco; UM, University of Michigan; ECE, extracapsular extension.

* Used as parameters in a nomogram to predict outcome.

$\dagger$ Risk of positive $\mathrm{SV}=(\mathrm{PSA})+[(\mathrm{GS}-6) \times 10]$.

* Risk of positive lymph nodes $=((2 / 3) \mathrm{PSA})+[(\mathrm{GS} 6) \times 10]$.

${ }^{\S}$ Risk of ECE $=[(3 / 2) \mathrm{PSA}]+[(\mathrm{GS} 3) \times 10]$.

prognosis and for directing therapy. Tables 3 and 4 summarize the criteria used to define patients who are considered to be at low risk of recurrence and death from several radiotherapy series. It can be seen in Table 3 that there is remarkable consistency among investigators from the United States, Austra- lia, and Canada, with the last group formally reaching a consensus. ${ }^{38}$ Although they are not quite as uniform, definitions of intermediate-risk disease also are very similar. Even investigators who have chosen to use equations or nomograms, as shown in Table 4, yield similar end results when they examined pa- 
tients with PSA levels $<10 \mathrm{ng} / \mathrm{mL}, \mathrm{GS} \leq 6$, and T1 or $\mathrm{T} 2$ tumors; thus, there is relatively little controversy about this category. With the growing use of risk stratification in both the current literature and in the language of clinical practice, the staging system here proposed is consistent with practice and improves on the current AJCC system without being overly complicated.

In the current analysis, we did not include the percent of positive cores despite a plethora of publications supporting the independent prognostic significance of this variable, because we do not possess such data. ${ }^{23,24,39-41}$ We recognize, however, that this growing body of literature suggests that, some time in the near future, such information may be useful for defining subcategories within the staging system. Until that day comes, we believe that incorporating the major clinical features described above would be an important step forward that is supported by a preponderance of the available clinical evidence.

In conclusion, every major recent series that has reported prostate cancer outcomes used a risk-classification scheme based on PSA and GS in addition to clinical $\mathrm{T}$ classification. None of the recently published series have reported outcomes using the current AJCC staging system. Now, we believe that it is time to incorporate the well recognized prognostic factors discussed here into a new staging system and that our proposed system represents a reasonable starting point.

\section{REFERENCES}

1. Cagiannos I, Karakiewicz P, Eastham JA, et al. A preoperative nomogram identifying decreased risk of positive pelvic lymph nodes in patients with prostate cancer. J Urol. 2003; 170:1798-1803.

2. Thompson IM, Pauler DK, Goodman PJ, et al. Prevalence of prostate cancer among men with a prostate-specific antigen level $<$ or $=4.0 \mathrm{ng}$ per milliliter. $N$ Engl J Med. 2004;350:2239-2246.

3. Albertsen PC, Hanley JA, Gleason DF, Barry MJ. Competing risk analysis of men aged 55 to 74 years at diagnosis managed conservatively for clinically localized prostate cancer [see comments]. JAMA. 1998;280:975-980.

4. Roach M, Lu J, Pilepich M, et al. Four prognostic groups predict long term survival from prostate cancer following radiotherapy alone on Radiation Therapy Oncology Group clinical trials. Int J Radiat Oncol Biol Phys. 2000;47:609-615.

5. D'Amico AV, Whittington R, Malkowicz SB, et al. Biochemical outcome after radical prostatectomy, external beam radiation therapy, or interstitial radiation therapy for clinically localized prostate cancer. JAMA. 1998;280:969-974.

6. Zelefsky MJ, Lyass O, Fuks Z, et al. Predictors of improved outcome for patients with localized prostate cancer treated with neoadjuvant androgen ablation therapy and threedimensional conformal radiotherapy. J Clin Oncol. 1998;16: 3380-3385.
7. Kattan MW, Zelefsky MJ, Kupelian PA, Scardino PT, Fuks Z, Leibel SA. Pretreatment nomogram for predicting the outcome of three-dimensional conformal radiotherapy in prostate cancer. J Clin Oncol. 2000;18:3352-3359.

8. Roach M 3rd, Weinberg V, McLaughlin PW, Grossfeld G, Sandler HM. Serum prostate-specific antigen and survival after external beam radiotherapy for carcinoma of the prostate. Urology. 2003;61:730-735.

9. D'Amico AV, Chen MH, Roehl KA, Catalona WJ. Preoperative PSA velocity and the risk of death from prostate cancer after radical prostatectomy. $N$ Engl J Med. 2004;351:125-135.

10. D'Amico AV, Cote $\mathrm{K}$, Loffredo $\mathrm{M}$, Renshaw AA, Chen MH. Pretreatment predictors of time to cancer specific death after prostate specific antigen failure. J Urol. 2003;169:13201324.

11. Williams SG, Duchesne GM, Millar JL, Pratt GR. Both pretreatment prostate-specific antigen level and posttreatment biochemical failure are independent predictors of overall survival after radiotherapy for prostate cancer. Int J Radiat Oncol Biol Phys. 2004;60:1082-1087.

12. Kwan W, Pickles T, Duncan G, et al. PSA failure and the risk of death in prostate cancer patients treated with radiotherapy. Int J Radiat Oncol Biol Phys. 2004;60:10401046.

13. Weinberg V, Roach M, McLaughlin P, Sandler H.A new staging system for prostate cancer based on T-stage, Gleason score and PSA improves the prediction of survival. Paper presented at: Proceedings of the American Society for Therapeutic Radiology and Oncology, November 4-8, 2001; San Francisco, Calif.

14. American Society for Therapeutic Radiology and Oncology. Consensus statement: guidelines for PSA following radiation therapy. Int J Radiat Oncol Biol Phys. 1997;37:10351041.

15. Kaplan EL, Meier P. Non-parameteric estimation from incomplete observations. J Am Stat Assoc. 1958;53:457-481.

16. Cox DR. Regression models and life tables. J R Stat Soc. 1972;34:187-202.

17. Fleming ID, Cooper JS, Henson DE, et al, eds. AJCC Cancer Staging Manual. 5 ed. Philadelphia: Lippincott-Raven; 1998.

18. Crook J, Ludgate C, Malone S, et al. Report of a multicenter Canadian Phase III randomized trial of 3 months vs. 8 months neoadjuvant androgen deprivation before standard-dose radiotherapy for clinically localized prostate cancer. Int J Radiat Oncol Biol Phys. 2004;60:15-23.

19. Cooperberg MR, Lubeck DP, Mehta SS, Carroll PR. Time trends in clinical risk stratification for prostate cancer: implications for outcomes (data from CaPSURE). $J$ Urol. 2003;170(6 Pt 2):S21-S25; discussion,S26-S27.

20. Kupelian PA, Potters L, Khuntia D, et al. Radical prostatectomy, external beam radiotherapy $<72$ Gy, external beam radiotherapy $>$ or $=72$ Gy, permanent seed implantation, or combined seeds/external beam radiotherapy for stage T1-T2 prostate cancer. Int J Radiat Oncol Biol Phys. 2004; 58:25-33.

21. Lattanzi JP, Hanlon AL, Hanks GE. Early stage prostate cancer treated with radiation therapy: stratifying an intermediate risk group. Int J Radiat Oncol Biol Phys. 1997;38:569573.

22. Chism DB, Hanlon AL, Horwitz EM, Feigenberg SJ, Pollack A. A comparison of the single and double factor high-risk models for risk assignment of prostate cancer treated with 3D conformal radiotherapy. Int J Radiat Oncol Biol Phys. 2004;59:380-385. 
23. D'Amico AV, Keshaviah A, Manola J, et al. Clinical utility of the percentage of positive prostate biopsies in predicting prostate cancer-specific and overall survival after radiotherapy for patients with localized prostate cancer. Int $J$ Radiat Oncol Biol Phys. 2002;53:581-587.

24. D’Amico AV, Renshaw AA, Cote K, et al. Impact of the percentage of positive prostate cores on prostate cancer-specific mortality for patients with low or favorable intermediate-risk disease. J Clin Oncol. 2004;22:3726-3732.

25. Zietman AL, Chung CS, Coen JJ, Shipley WU. Ten-year outcome for men with localized prostate cancer treated with external radiation therapy: results of a cohort study. J Urol. 2004;171:210-214.

26. Selek U, Lee A, Levy L, Kuban DA. Utility of the percentage of positive prostate biopsies in predicting PSA outcome after radiotherapy for patients with clinically localized prostate cancer. Int J Radiat Oncol Biol Phys. 2003;57:963967.

27. Lee LN, Stock RG, Stone NN. Role of hormonal therapy in the management of intermediate- to high-risk prostate cancer treated with permanent radioactive seed implantation. Int J Radiat Oncol Biol Phys. 2002;52:444-452.

28. Potters L, Morgenstern C, Mullen EE, Fearn P, Jassal A, Kat$\tan$ M.Twelve year outcomes following permanent brachytherapy in patients with clinically localized prostate cancer. Paper presented at: Proceeding of the American Society for Therapeutic Radiology and Oncology; October 3-7, 2004; Atlanta, Ga.

29. Zelefsky MJ, Leibel SA, Gaudin PB, et al. Dose escalation with three-dimensional conformal radiation therapy affects the outcome in prostate cancer [see comments]. Int $J$ Radiat Oncol Biol Phys. 1998;41:491-500.

30. Zelefsky MJ, Fuks Z, Hunt M, et al. High-dose intensity modulated radiation therapy for prostate cancer: early toxicity and biochemical outcome in 772 patients. Int J Radiat Oncol Biol Phys. 2002;53:1111-1116.

31. Sylvester JE, Blasko JC, Grimm PD, Meier R, Malmgren JA. Ten-year biochemical relapse-free survival after external beam radiation and brachytherapy for localized prostate cancer: the Seattle experience. Int J Radiat Oncol Biol Phys. 2003;57:944-952.

32. Kuban DA, Thames HD, Levy LB, et al. Long-term multiinstitutional analysis of stage T1-T2 prostate cancer treated with radiotherapy in the PSA era. Int J Radiat Oncol Biol Phys. 2003;57:915-928.

33. Williams SG, Millar JL, Dally MJ, Sia S, Miles W, Duchesne GM. What defines intermediate-risk prostate cancer? Variability in published prognostic models. Int J Radiat Oncol Biol Phys. 2004;58:11-18.

34. Merrick GS, Butler WM, Galbreath RW, Lief JH, Adamovich E. Relationship between percent positive biopsies and biochemical outcome after permanent interstitial brachytherapy for clinically organ-confined carcinoma of the prostate gland. Int J Radiat Oncol Biol Phys. 2002;52:664-673.

35. Michalski JM, Purdy JA, Winter K, et al. Preliminary report of toxicity following 3D radiation therapy for prostate cancer on 3DOG/RTOG 9406. Int J Radiat Oncol Biol Phys. 1999;46:397-402.

36. Speight JL, Weinberg VK, McLaughlin PW, Roach M, Sandler HM.3D conformal radiotherapy improves PSA failure rates for intermediate risk patients at conventional doses. Paper presented at: Proceedings of the American Society for Therapeutic Radiology and Oncology; October 31-November 4, 1999; San Antonio, Tex.

37. Roach M 3rd, Chen A, Song J, Diaz A, Presti J Jr, Carroll P. Pretreatment prostate-specific antigen and Gleason score predict the risk of extracapsular extension and the risk of failure following radiotherapy in patients with clinically localized prostate cancer. Semin Urol Oncol. 2000;18:108114.

38. Lukka H, Warde P, Pickles T, Morton G, Brundage M, Souhami L. Controversies in prostate cancer radiotherapy: consensus development. Can J Urol. 2001;8:1314-1322.

39. D'Amico AV, Whittington R, Malkowicz SB, et al. Clinical utility of the percentage of positive prostate biopsies in defining biochemical outcome after radical prostatectomy for patients with clinically localized prostate cancer. J Clin Oncol. 2000;18:1164-1172.

40. Kestin LL, Goldstein NS, Vicini FA, Martinez AA. Percentage of positive biopsy cores as predictor of clinical outcome in prostate cancer treated with radiotherapy. J Urol. 2002;168: 1994-1999.

41. Grossfeld GD, Latini DM, Lubeck DP, et al. Predicting disease recurrence in intermediate and high-risk patients undergoing radical prostatectomy using percent positive biopsies: results from CaPSURE. Urology. 2002;59:560-565. 